\title{
ANKLE PROPRIOCEPTION IN INDIVIDUALS WITH KNEE OSTEOARTHRITIS AND NORMALS
}

\section{SREERAJ S.R. ${ }^{1 *}$ AND NAMRATHA BAGUL²}

1MGM College of Physiotherapy, Sector 18, Kamothe, Navi Mumbai- 410209, MS, India.

2B.J. Wadia Hospital for Children, Parel, Mumbai- 400012, MS, India.

${ }^{*}$ Corresponding Author: Email-sreeraj_sr@ymail.com

Received: June 06, 2012; Accepted: June 12, 2012

\begin{abstract}
-
Objective- To test the hypotheses that patients with knee OA will have an altered proprioception in ankle.

Methods- This study compared the ankle proprioception levels of a group of 35 clinically and radiographically diagnosed cases of unilateral knee OA by the orthopaedic department of MGM Medical College, Navi Mumbai to a control group of 35 normal subjects. The data was analyzed by an unpaired ' $\mathrm{t}$ ' test.

Results- Since $t_{c a l}>t_{t a b}$ and $P$ value is $<0.01$ we reject $\mathrm{H}_{0}$ and accept $\mathrm{H}_{\mathrm{a}}$ i.e. there is significant difference in ankle proprioception in $\mathrm{OA}$ knee cases compared to normal's.

Conclusion- There is significant difference in ankle proprioception in OA knee cases compared to normals. These results confirm the strong association between reduced proprioception in ankle in cases of osteoarthritis of knees.

Keywords- ankle proprioception, patients with knee OA, unpaired ' $\mathrm{t}$ ' test

Citation: Sreeraj S.R. and Namratha Bagul (2012) Ankle Proprioception in Individuals with Knee Osteoarthritis and Normals. International Journal of Medical and Clinical Research, ISSN:0976-5530 \& E-ISSN:0976-5549, Volume 3, Issue 5, pp.-164-167.

Copyright: Copyright@2012 Sreeraj S.R. and Namratha Bagul. This is an open-access article distributed under the terms of the Creative Commons Attribution License, which permits unrestricted use, distribution, and reproduction in any medium, provided the original author and source are credited.
\end{abstract}

\section{Introduction}

Osteoarthritis $(\mathrm{OA})$ was estimated to be the 10th leading cause of non-fatal burden in the world in 1990 , accounting for $2.8 \%$ of total Years Lived with Disability (YLD), around the same percentage as schizophrenia and congenital anomalies [1]. In the Version 2 estimates for the Global Burden of Disease 2000 study, published in the World Health Report 2002(5), OA is the 4th leading cause of YLDs at global level, accounting for $3.0 \%$ of total global YLDs [2]. The prevalence of arthritis is expected to increase by $57 \%$ by 2020 , and even more concerning than the actual prevalence of the disease is the high percentage of those patients $(66 \%)$ that will incur associated activity limitations [3].

Osteoarthritis $(\mathrm{OA})$ is a generally progressive condition that involves both anabolic and catabolic mechanisms within the articular cartilage and bone of synovial joints in response to both internal and external factors [4]. Among these factors are age [5,6], genetics [7], joint/ limb alignment [8-12], joint injury [13], female gender14 and obesity $[15,16]$.
Clinically, OA of the knee is characterized predominantly by pain and limitations in the ability to perform activities of daily living, such as stair climbing, walking, and household chores [17]. These limitations are partly due to joint stiffness, decrease of muscle strength, and proprioception deficits [18-23].

Proprioception, the perception of limb position in space, is derived from afferent signals originating primarily from musculotendinous and joint receptors. Proprioception is critical to the maintenance of joint stability. Studies have demonstrated that knee proprioception is less accurate in patients with knee osteoarthritis versus elderly control subjects, in healthy older versus younger subjects, and in the setting of other conditions affecting the knee including anterior cruciate ligament deficiency and hypermobility syndrome $[24,25]$

Knee OA appear to present with mechanical stability changes at the ankle-subtalar joint complex [26]. As knee OA continues to progress, the alignment of the lower extremity also continues to change because of the abnormal contact pressures that develop 
within the medial and lateral compartments of the tibiofemoral articulation [27]. As the severity of knee OA progresses, changes in the alignment of the lower extremity do occur (increased knee valgus/varus), including deviation to the ankle joint complex (altered axis of rotation) [27]. With recent evidence demonstrating that altered kinematics at the knee joint lead to premature development of ankle OA secondary to the progression of knee OA, the question arises whether ankle joint kinematics are also influenced [27].

Degenerative changes in the knee joint are also thought to increase postural sway [28]. According to most previous clinical studies, patients with knee OA have impaired postural control [2933] but there is no significant difference in postural stability found between those patients suffering from hip OA and their healthy controls [34]. Studies demonstrated an association between increased postural sway and reduced quadriceps strength but no clear association with reduced proprioception in patients with knee osteoarthritis [31].

Previous studies have established that deviations in the normal knee biomechanical axes as a result of lower extremity malalignment that accompanies moderate to severe knee OA cases could very well affect the mechanics of the ankle joint [26]. The same can be suspected in the case of ankle proprioception in knee OA events since there are reports of increased postural sway and impaired postural control. In view of the wide spread prevalence of OA knee such studies are necessary to determine whether treatment, especially physical therapy treatments of patients with knee OA should also focus on the ankle to help improve long-term function as well as prevent the development of ankle OA. Therefore, the purpose of this study is to examine altered ankle proprioception in patients with knee OA. We hypothesize that patients with knee OA will have an altered proprioception in ankle.

\section{Methods}

This study compared the ankle proprioception levels of a group of 35 clinically and radio-graphically diagnosed cases of unilateral knee OA by the orthopedic department of MGM Medical College, Navi Mumbai to a control group of 35 normal subjects. Informed consent obtained from the subjects to carry out the study. Exclusion criteria were polyarthritis, the presence of rheumatoid arthritis or other systemic inflammatory arthropathies, knee surgery within the last 12 months or a history of knee arthroplastic surgery, intraarticular corticosteroid injections into either knee within the previous 3 months, patients with a history of knee/ankle ligament deficiency, obesity and congenital/acquired deformities of ankle.

\section{Procedure}

The subjects were seated on the high sitting position on a high plinth with their feet hanging and with the knee flexed to 90 degrees position. The foot in neutral and 0 degrees of inversion and eversion. The fulcrum of the goniometer positioned over the lateral aspect of the lateral malleolus, proximal arm aligned with the lateral midline of the fibula using head of the fibula as the reference point and the distal arm aligned parallel to the lateral aspect of the fifth metatarsal. The subjects were blind folded. The tester should move ankle into the passive dorsiflexion and plantar flexion ten times and place in the particular position of 15 degrees of plantar flexion. This was considered to be a target angle (angle 1). This position is maintained for fifteen seconds and asks the subject to remember this measure of angle. Then the patient was asked to move ankle ten times actively and position the ankle to the previous target angle. Measure this new angle using the same goniometer (angle 2). The difference between initial and final angle noted and taken for analysis.

\section{Statistical Analysis}

The difference between angle 1 and angle 2 were considered as proprioceptive error. The data was analyzed by an unpaired 't' test the result of which is given in table 1.

Table 1- t-Test: Two-Sample Assuming Unequal Variances

\begin{tabular}{|lll|} 
& OA Knee & Normal \\
\hline Mean & 10.57142857 & 4.2 \\
Variance & 22.25210084 & 11.63529412 \\
Observations & 35 & 35 \\
Hypothesized Mean Difference & 0 & \\
df & 62 & \\
t Stat & 6.475178554 & \\
$P(T \leq t)$ one-tail & $8.6296 \mathrm{E}-09$ & \\
$t$ Critical one-tail & 1.669804163 & \\
$P(T \leq t)$ two-tail & $1.72592 \mathrm{E}-08$ & \\
$t$ Critical two-tail & 1.998971498 & \\
\hline
\end{tabular}

\section{Results}

Since $t_{\text {cal }}>t_{\text {tab }}$ and $P$ value is $<0.01$ we reject $H_{0}$ and accept $H_{a}$ i.e. there is significant difference in ankle proprioception in $\mathrm{OA}$ knee cases compared to normal one.

\section{Discussion}

The purpose of this study was to examine altered ankle proprioception in patients with knee OA. We hypothesized that patients with knee OA will have an altered proprioception in ankle. Our results show that there is significant difference in ankle proprioception in OA knee cases compared to normal one ( $P$ value is < 0.01). To our knowledge, this is the first study to evaluate the alterations in ankle proprioception in OA knee cases.

Studies establish that there is altered ankle joint mechanics and deviations in ankle joint alignment secondary to the structural changes at the knee following OA knee [35]. People with knee OA modify their walking patterns at some point after disease onset and potentially increase the amounts of compensation, most notably in the later stages of the disease [36]. Hassan B S et al concluded that compared with age and sex matched controls, subjects with symptomatic knee OA have quadriceps weakness, reduced knee proprioception, and increased postural sway [37]. Quadriceps strength and proprioception are clearly important for balance control. Loss of balance as suggested by various authors are pain [38], reduced loading due to pain [39], knee flexion contractures [40] apart from altered joint mechanics and muscle weakness. Daina L. Sturnieks, Anne Tiedemann et al concluded in their study that arthritic group had reduced knee and ankle strength compared to the non arthritic group. Strength deficits in people with lower extremity arthritis have been suggested to be due to disease-associated pain, joint effusion, articular damage, and secondary muscle atrophy [41].

People with medial compartment knee OA exhibit a more pronated foot type compared to controls [42]. The authors went on to suggest that people with medial compartment knee OA often display 
genu varum malalignment of the knee, which has been shown to increase the risk of development and progression of knee OA. Genu varum malalignment of the knee may lead to compensatory foot pronation to enable the foot to be plantigrade when weightbearing. Their observations suggest the changes occurring in ankle joint associated to OA knee.

In a recent study, a simulated genu varum walking pattern was found to increase the subtalar joint pronation moment, suggesting that frontal plane angular deformities of the knee can alter the kinetic and kinematics of the foot during gait [43]. Increased foot pronation could potentially reduce the adduction moment by shifting the centre of pressure laterally, so it is possible that the foot adapts to reduce the load on the medial compartment and can be subjected to ankle injuries secondary to OA knee.

Alterations in sensorimotor function and neuromuscular control of proximal lower extremity joints are consistently observed in patients with chronic ankle instability (CAI). These proximal changes have manifested themselves as deficits in force production, kinematic pattern changes, and deficits in muscle activation patterns about the knee and hip during a variety of tasks and testing techniques [44]. The above said changes can be observed in OA knee cases also.

It is now understood that there is an association exist in altered ankle proprioception in OA knee cases. Further studies need to conduct on wider platform with better tools available to establish this hypothesis and the exact reason for the same.

It is acknowledged that this study has certain limitations. This study was conducted on unilateral OA knee cases due mainly to the availability of cases during the study. There were no diagnostic tools used like Kellgren-Lawrence classification grades, WOMAC Osteoarthritis Index etc during this study. Further studies can be conducted using tools like these for a better and accurate comparison in the proprioceptive error in groups.

In summary, we found that there is significant difference in ankle proprioception in OA knee cases compared to normals. These results confirm the strong association between reduced proprioception in ankle and osteoarthritis of knees.

\section{Conclusions}

The result of this study shows that there is role of altered ankle proprioception in loss of balance in OA knee cases. Therefore, we emphasize proprioception and strength training programs to be included for ankle also in the rehabilitation program for OA knee.

\section{References}

[1] Murray C.J.L., Lopez A.D. (1997) Global Burden of Disease Study.

[2] World Health Organization (2002) World Health Report. Reducing Risks, Promoting Healthy Life.

[3] Brandt K., Doherty M., Lohmander S. (2003) Osteoarthritis, 2nd edition, 172-177.

[4] Carol Muehleman, Arkady Margulis, Won C. Bae, Koichi Masuda (2010) BMC Medicine, 8,48.

[5] Gensburger D., Arlot M., Sornay-Rendu E., Roux J.P., Delmas P. (2009) Arthritis Rheu. m., 15, 336-343.

[6] Loeser R.F. (2009) Osteoarthritis Cartilage, 17, 971-979.

[7] MacGregor A.J., Li Q., Spector T.D., Williams F.M. (2009) Rheumtology, 48, 277-280.
[8] Issa S.N., Dunlop D., Chang A., Song J., Prasad P.V., Guermazi A., Peterfy C., Cahue S., Marshall M., Kapoor D., Hayes K., Sharma L. (2008) Arthritis Rheum, 57, 398-406.

[9] Kalichman L., Zhu Zhang Y., Niu J., Gale D., Felson D.T., Hunter D. (2007) Osteoarthritis Cartilage, 15, 1235-1240.

[10]Hunter D.J., Niu J., Felson D.T., Harvey W.F., Gross K.D., McCree P., Aliabadi P., Sack B., Zhang Y. (2007) Arthritis Rheum., 56, 1212-1218.

[11]Hunter D.J., Sharma L., Skaife T. (2009) J. Bone Joint Surg. 91(S1), 85-89.

[12]Tanamas S., Hanna F.S., Cicuttini F.M., Wluka A.E., Berry P., Urquhart D.M. (2009) Arthritis Rheum., 61, 459-467.

[13]Englund M., Guermazi A., Roemer F.W., Aliabadi P., Yang M., Lewis C.E., Torner J., Nevitt M.C., Sack B., Felson D.T. (2009) Arthritis Rheum., 60, 831-839.

[14]Hanna F.S., Teichtahl A.J., Wluka A.E., Wang Y., Urquhart D.M., English D.R., Giles G.G., Cicuttini F.M. (2009) Menopause, 16, 624-625.

[15]Grotle M., Hagen K.B., Natvig B., Dahl F.A., Kvien T.K. (2008) BMC Musculoskelet Disord., 9, 1-5.

[16]Claessen H., Arndt V., Drath C., Brenner H. (2009) Occup. Environ. Med., 66, 402-409.

[17]Felson D.T., Zhang Y. (1998) Arthritis Rheum., 41, 1343-1355.

[18]Van Baar M.E., Dekker J., Lemmens J.A., Oostendorp R.A., Bijlsma J.W. (1998) J. Rheumatol., 25, 125-133.

[19]Fransen M., McConnell S., Bell M. (2002) J. Rheumatol, 29, 1737-45.

[20]Steultjens M.P., Dekker J., Van Baar M.E., Oostendorp R.A., Bijlsma J.W. (2001) Clin. Rehabil., 15, 331-341.

[21]Slemenda C., Brandt K.D., Heilman D.K., Mazzuca S., Braunstein E.M., Katz B.P., et al. (1997) Ann. Intern. Med., 127, 97-104.

[22]Eyigor S., Hepguler S., Capaci K. (2004) Clin. Rheumatol, 23, 109-115

[23]Vilalta C., Nunez M., Segur J.M., Domingo A., Carbonell J.A., Macule F. (2004) Clin. Rheumatol., 23, 501-504.

[24]Sharma L. (1999) Rheumatic Diseases Clinics of North America, 25(2), 299-314.

[25]Sharma L., Pai Y.C. (1997) Current Opinion in Rheumatology, 9(3), 253-258.

[26]Tricia J. Hubbard, Charlie Hicks-Little, Mitchell Cordova (2010) Arch. Phys. Med. Rehabil., 91, 73-77.

[27]Tallroth K., Harilainen A., Kerttula L., Sayed R. (2008) Arch. Orthop. Trauma Surg., 128, 550-560.

[28]Spirduso W.W., Francis K.L., MacRae P.G. (2005) Anonymous Physical Dimension of Aging, 2nd edition, Champaign: Human Kinetics.

[29]Hurley M.V., Scott D.L., Rees J., Newham D.J. (1997) Ann. Rheum. Dis., 56, 641-648.

[30]Wegener L., Kisner C., Nichols D. (1997) J. Orthop. Sports Phys. Ther., 25, 13-18.

[31]Hassan B.S., Mockett S., Doherty M. (2001) Ann. Rheum. Dis., 60, 612-618.

[32]Hinman R.S., Bennell K.L., Metcalf B.R., Crossley K.M. (2002) Rheumatology, 41, 1388-1394.

[33]Masui T., Hasegawa Y., Yamaguchi J., et al. (2006) J. Orthop. Sci., 11, 353-358.

[34]Arokoski J.P., Leinonen V., Arokoski M.H., et al. (2006) Gait 
Posture, 23, 45-50.

[35]Hubbard T.J., Hicks-Little C., Cordova M. (2010) Arch. Phys. Med. Rehabil. 91(1), 73-77.

[36]Mundermann A., Dyrby C., Andriacchi T. (2005) Arthritis Rheum., 52, 2835-2844.

[37]Hassan B.S., Mockett S., Doherty M. (2001) Ann. Rheum. Dis., 60, 612-618.

[38]Arvidsson I., Eriksson E., Knutsson E.S.A., Arner S. (1986) Orthopedics, 9, 1415-1419.

[39]Hurwitz D.E., Ryals A.R., Block J.A., Sharma L., Schnitzer T.J., Andriacchi T.P. (2000) J. Orthop., 18, 572-579.

[40]Brocklehurst J.C., Robertson D., James-Groom P. (1982) J. Am. Geriatr. Soc., 30, 534-538.

[41]Daina L. Sturnieks, Anne Tiedemann (2004) The Journal of Rheumatology, 31, 2272-2279.

[42]Pazit Levinger, Hylton B. Menz (2010) Journal of Foot and Ankle Research, 3, 29.

[43]Van Gheluwe B., Kirby K.A., Hagman F. (2005) J. Am. Podiatr Med. Assoc., 95, 531-541. 